\title{
A reply to my critics
}

\author{
Joshua Foa Dienstag
}

Dear Friends! Dearer Opponents! I find myself strangely cheered by your criticisms. At any rate, I find them easier to read than my own letter, written some time ago, the words of which now return to haunt me with their crudeness. I am in your debt.

If I speak in another's guise, I will at least not seek to emulate his hostility to the opinions of others nor his paranoia about their motives. On the contrary, I think our exchange will reveal that the spirit of friendship can survive disagreement and, in fact, even be strengthened by it.

But again I remind you that we can only disagree and be nourished by our dissensus after the film has ended and not while it still plays. I remain undaunted in the thought that this small community of five or six, like the larger one of which we are but a part, will be strengthened by an equal, reciprocal and boisterous conversation and not by a quiet collective viewing, however pleasing the latter might be.

I have not, in this response, spent much time on the particulars of the two films I discuss at length in my "Letter to M. Cavell." While I want to acknowledge the many fine points and interesting interpretations of the films that the respondents make, I do not have the space to debate particulars and I believe our audience would, in any case, find it tiresome to do so any further. So, I have focused on what I take to be the larger points.

One theme I have found in several of these objections is the following: that I have spoken wrongly for Cavell; that I have made him 
mean what he did not mean; that I have made him mean something particular when he meant something abstract; that I have made him command when he meant only to indicate or to suggest or to exemplify. To this charge, I might plead a qualified "guilty," but the qualification is an important one.

As several of the commentators remind me, Cavell is the author of Must We Mean What We Say?, a book which indicates the difficulty of answering that question, and also a book which insists that meaning is not something fully under the command of an author. At the very least, I think it is wrong for my respondents to rely on what they believe Cavell meant; more important is what his work means to us now, how his claims (and those of others like him) about cinema and about our culture resonate today and what effect they will have going forward. In particular, I think it is of no avail to say that Cavell has no desire to command or instruct if his words are taken for instructions or commandments. One could say the same of many philosophers or sages, that their followers are more zealous than they ever were. We must judge also by effects and not merely by intentions.

I will, therefore, repeat my opening sentiment: I have no wish to wrong Cavell. If there is an agreement that fosters the disagreements aired in these pages, it is that we have all read and learned from him. I have tried only to speak for myself to him and to others, like the respondents, who share similar thoughts about what is best for our democracy and our culture. If I have misheard him, I apologize, but that is ultimately something for the reader to judge. And, in judging, I would ask the reader to consider more the substance of the argument between us; that is, the matter of our conversation and not the words or voices we used or intended in speaking of it.

Let me (very) briefly rehearse my position, the better to answer my detractors. I have argued against an optimistic account of the relation between film and democracy. I have claimed that the pleasures of cinema come at the expense of democracy, not in its service. I oppose the comfortable assumption that artistic achievement in this genre and democratic freedom naturally support one another. 
Can we learn to be better citizens and better people by observing a representation of human life that is meant to instruct or inspire us? I maintain - to the contrary, like Rousseau - that this misunderstands the relationship between original and copy, even more so in the medium of film than in the medium of theater. Although the immediate focus of the essay is M. Cavell, the larger target is the general Enlightenment position, revived today in more than one quarter (e.g., William Connolly, Richard Rorty, Robert Pippin, Jacques Rancière) that popular film can serve to instruct us in democracy. Indeed, perhaps here is the place to re-emphasize that I criticize Cavell not because I think he is the worst of these figures, but because he is the best of them and puts forth the most powerful and subtle case for his position, in addition to all the other ways in which his philosophy improves us.

Still, I contest his position both on specific and general points. I contest, first, his interpretation of The Philadelphia Story, a film that he has said exemplifies the connection between Emersonian perfectionism and the "remarriage comedies" of the 1930s and 1940s. Rather than demonstrating moral improvement, the film reveals the dangers and pleasures involved in the representation of the instability of erotic relations. It warns, I argue, against thinking that we can learn to democratize by watching a representation of democracy, however artful.

In the second section, I turn from The Philadelphia Story to its dark twin The Rules of the Game (La Règle du jeu), a film made at roughly the same time with roughly the same plot but with a much more pessimistic account of the relationship between eros and politics. In this film, instead of the miraculous resolution of eros and law, we see the vicious conflicts between these two more starkly depicted; in the end, the erotic desires of the characters are brutally policed by social regulations that appear beyond the control of any individual. Unlike The Philadelphia Story, The Rules of the Game was not a commercial success and only decades after its initial release became a darling of film critics. The reason, I argue, is not hard to understand: its pessimistic depiction of democracy indicts its audience and their desire for instruction and moral uplift from aesthetic works. This tragedy of remarriage, 
I maintain, would be a better instructor of a democratic community, if such a community were prepared to listen. That it is not is one of the obstacles that aesthetic optimists fail to acknowledge.

In the final section, to get to the root of our differences, I take up more directly the aesthetic, phenomenological and ontological issues that the first two sections have raised. I first consider Cavell's contention that time is a "barrier" between film and audience and argue, to the contrary, that time is in fact the medium that forms the aesthetic connection between humans and film, something we can understand better by contrasting cinema with television.

Next, I argue that we must understand film as an interruption of the sociability and mutual recognition that we enjoy, potentially at least, with other humans in democratic relations. Our ability to see pictures as pictures in the first place (as animals cannot) has its root in our recognition of the plurality of other views that actually exist. Film takes advantage of this human ability for picture-seeing, but also takes it out of its ordinary and original social context and returns it to a kind of animal captivation. Rather than expanding our vision, I maintain, cinema in fact narrows it and deprives us (quite pleasantly, it must be admitted) of the relationality and independence we ought to enjoy as free, autonomous beings.

Whatever the content of particular films, the medium itself does not empower its audience but, on the contrary, disables us. Rather than teaching us how to democratize, it substitutes an experience that feels instructional but is actually enervating. While I do not repeat Rousseau's claim that the theater simply substitutes illusion for reality, I do echo his concern that the spectacular experience can feel empowering when it is actually politically crippling. We must take the hard lesson that our pleasures and our freedom are in some contest with one another, that we may have to sacrifice some of the former to secure the latter.

I take it as some confirmation of my siting of Cavell with the other figures I mentioned that Clare Woodford, in her essay, puts him together with Jacques Rancière and forges a defense of film's democratic potential from this alliance. While this defense is attractive, I am not certain 
that it is in fact Cavell's defense, nor that, in fact, what it asks of us is really possible.

But first I must object to hearing my own position described as a "cynical" one. Never that! Perhaps it will surprise some readers that, having called myself a pessimist, I take offense at being labeled a cynic. Are not the two words more or less synonymous? I think not. Though they often go together in public consciousness today, I have taken some pains in the past to differentiate them and now I fear I must do so again.

Originally, of course, the Cynics were so called for their "doglike" behavior - they were indifferent to human conventions and mocked traditional morality. In modern times, however, cynicism has come to mean a more generalized indifference and even an active suspicion of the motives of others. To be a cynic now is akin to thinking the worst of others and that, I take it, is what Woodford means to accuse me of when she claims that I express "disappointment in the human condition" (p. 90). I hope that I do no such thing.

On the contrary, while it is true that I avoid optimism and suggest that others avoid it as well, I take that to mean that I, in fact, am more accepting of the people who exist today, with all their flaws, and ask others to refrain from fantasizing about them or projecting onto them [n. b.] qualities that they do not possess. Is it wrong of me to ask that we take humans as they are? Rousseau was not embarrassed to do so and neither am I. As to what humans might be, my account creates no limitations but asks only that we not proceed by the imitation of the imaginary beings we see on film as if they were human.

On the topic of imitation, Woodford defends Cavell by an ingenious argument that creates two kinds of exemplarity. There is, she argues, exemplarity of the ordinary kind, where a model is held up for one to imitate; and then a second kind, which I will call "meta-exemplarity," where an exemplar is offered not that one should imitate its traits or behaviors but only its meta-characteristic of being unique or individual. I attack the first, Woodford claims, but Cavell only defends the second.

It is true that Cavell, following Emerson and Nietzsche, speaks of this kind of meta-exemplarity. But I do not think that he speaks of it 
exclusively. Indeed, I do not know how we could really think about it exclusively, certainly not in relation to film. It is true enough, in a logical sense, that we can distinguish between the imitation of a particular trait and the more general, if vague, sense in which an example of individuality provokes an admiration that is not confined to the traits of the individual on display. However, if a general encouragement of individuality was all that was being urged, why would Cavell repeatedly make it so hard for us to distinguish this point from the other by suggesting films with such avatars of imitability? What man does not start to imitate Cary Grant's suave graciousness, in all its fastidious detail, after watching his comedies of remarriage? I cannot say whether Katharine Hepburn inspires an equivalent reaction, but it would be no surprise to me were it so. Surely Cavell is aware of this? Surely, too, he is aware of how such imitation of mannerisms, costumes, dialogue and poses is the most ordinary result of a film's popularity?

If the meta-exemplarity occurs at all, surely it must occur through and after the ordinary kind? We might (might!), on reflection, see that there is more to C. K. Dexter Haven than charm and wit and a well-tailored wardrobe, but I doubt whether we could ever be brought to such reflection if we had not been charmed by the wit and wardrobe in the first place. In any case, Cavell does not simply make the Emersonian case that we should each be ourselves, but offers us particular models that he goes out of his way to describe at great length. Why review so many films in such detail if the point is to abstract away from all of them? Indeed, I would make the same claim about Emerson. Do we really think that he wrote Representative Men in order to inspire us only generally "to be more active ... citizens" (p. 92)? Does it not make more sense to think that we are supposed to both learn particular lessons from particular figures, as well as have the meta-inspiration to be our own best selves? So I am not sure that the two kinds of exemplarity can be so neatly separated in practice, nor that Cavell intended to do so.

While I think Woodford is right to find a resonance between Cavell and Rancière, this does not, naturally, incline me toward the view of either. I have my doubts as to whether Cavell would really go as far with 
Rancière in emancipating the spectator as Woodford believes. But, let me set this aside and acknowledge a larger point on which I believe we can agree: surely a democratic conversation to aspire to is one in which each participant trusts his own judgment or, at least, does not defer automatically to the judgment of any other. To be able to make one's own judgments, and to be able to live by them, ought to be understood as the core capacities of a free citizenry. However, in order to distinguish judgments from whims, they must meet with contrary views and have some cause to respect them so that they earn their status in a real contest of faculties.

At a certain point, therefore, I wonder if the model of emancipated judgment begins to collapse in on itself. Woodford makes the point, quite correctly, that Rancière has no reason to favor a particular genre, like the comedies of remarriage, as a focus of judgment: "all films and all types of performance can play their role in our journeys of self-reflection" (p. 97). Indeed. But why stop there? Why think that judgment of art is any different from judgment of nature or politics or technology? When trust in our own judgment becomes our only principle, there is no one and no one thing that we need to pay attention to. And, if we choose our own objects of reflection, we are very close to choosing our own conclusions.

Alexis de Tocqueville saw this characteristic already developing in the Americans of the 1830s and he deplored its logical consequence: when we trust only ourselves, we cut ourselves off from others - not just from their domination or possible wisdom, but in every way. Each person seeks "the light of truth nowhere but in their own understandings. Every one then attempts to be his own sufficient guide." ${ }^{1}$ Rancière thinks of contact with others' judgment as domination, never as education. But if everyone's judgment is perfectly independent, no one is forced to confront the opinion of any other. For that to work would require more than Jacotot's "equal intelligence," it would require what is impossible: that everyone's judgment be equally true.

Alexis de Tocqueville, Democracy in America (New York: Appleton, 1904), vol. 2, ch. 22, p. 489. 
If there is an important difference between Cavell and Rancière to point to here, I would say that, in focusing on the value of conversation, Cavell makes the claim (as Rancière does not) that we cannot pursue our own emancipation in intellectual isolation from others. On this much, at least, he and I concur. (I will return to the topic of conversation later.) Cavell's aversion to conformity is never a rejection of education and conversation. If all we have to learn from others is that we too can judge for ourselves then, once we have learned this lesson, there would be no need to ever converse again.

It is clear that Woodford rejects such an isolated life and insists that we live in conversation with other exemplars. But my question is: what are we meant to learn from such partners? Must we be reminded over and over to be ourselves (does it take that much reminding?) and yet never imitate them in any particular way? Again, the firm distinction between two kinds of exemplarity seems to fall apart in practice. So we must ask again: if the democratic citizen is prone to be influenced both by other people, as well as by art and the natural world, will our theory say nothing about which of these might be healthier and which more dangerous? That we are emancipated cannot mean that we are invulnerable.

My concern has been that in watching film we have a kind of hidden experience of domination that degrades our character as democratic citizens who might otherwise be engaged in reciprocal relations with our peers. Woodford reports that her own mind in fact wanders during her visits to the cinema. I am very glad to hear it. Would that it happened more often and to more people! But I can only speculate that the films in question must have been very bad to fail to hold her attention when they had so many means at hand to do so. If we all found cinema routinely unabsorbing we would all surely cease to attend, and then my concerns would be answered in a different way.

I am no enemy of solitude and I share with Woodford the sense that real solitude can contribute greatly to our being. Is it not a strange fact of modern life, however, that anyone would seek solitude in a cinema, a crowded room full of sound and light? I will not insist, like Emerson's 
sometime friend Thoreau, that we abjure society and live in the woods to find ourselves. But, if asked to choose between the two models, I would say that at least Thoreau knew what he was about and chose the shorter path to his goal, if not the only one.

Finally, I am glad that we can agree that finding the balance between moment and law is the difficult task on which we are endeavored. Even if we disagree on the means, the task itself is of such overriding importance that the more we reflect upon it, the better off we will be. Only we must really reflect upon solutions and not let them be reflected or projected onto us.

"Saturday Night," though he declines Cavell's voice, probably speaks more purely in Cavell's generous spirit than any other in this volume. Like Woodford, Tracy Strong believes that I misconstrue how Cavell thinks film educates us, though his version of the proper account is at some distance from Woodford's. Film does not "teach us lessons," he says, "Rather film can prepare us by making evident a possibility" (p. 114). Again, I wonder whether this distinction can remain as firm as Strong would wish it - how long can we admire something as a possibility before seeking to imitate it? - but let me return to this later.

First, I want to make more explicit something that I hope my readers already appreciate: I know that Cavell is not d'Alembert. In putting one in the place of another, I do not mean to imply that their theories overlap in every detail. While d'Alembert was a sophisticated man, his aesthetics would be hard to defend today. He did indeed seem to possess a cruder account of the good of theater than Cavell's far more complex defense of film (and the other arts, such as music). I do not believe I accused Cavell of being d'Alembert.

Rather, I put one in place of another because of their parallel employment of the arts in relation to politics. D'Alembert, like Cavell, suggested that we take the best examples of a medium and isolate their effects on a potential audience. I, like Rousseau, insist that we cannot really hope to expose a population to some examples of a medium that improve it while allowing other examples (the great majority) to degrade it - we must evaluate the medium as a whole. And we must evaluate the effect 
of the structure of its experience and not simply the content of its best instances.

D'Alembert suggested that the Parisian theater could be purified for Geneva by maintaining strong laws against the poor behavior of actors. Cavell (and Strong) tell us that we are to respond, or to be taught responsiveness, by good films. Such films are supposed to be those, as Strong reminds us, that can withstand criticism. But how are we to find them? Are Cavellian censors to be established who will keep the worst films from us? More importantly, how did Cavell find these films? Like the nineteenth-century music critic, he must have endured many hundred poor operas to find the few worth listening to a second time. What effect did these bad films he had to endure have on his character? Perhaps none at all in his case, his genius being so remarkable to begin with. But for the rest of us? Whoever gives us a theory of good film and its effects must give us an account of the effects of bad film, or else give up the title of social critic for that of curator of fine arts. Either a censor chooses the good films for us and we are the slave of that person's taste or we endure a genre in toto and in populo (for the films that we see will be tuned to the taste of the public, not that of the philosopher).

We often laugh at self-appointed moral censors who judge films bad without ever having seen them. Does not Cavell encourage a similar conceit? That we could know which are the good films before we see them?

I admit that Milton's model of a "meet and happy conversation" as a basis for politics is a charming one, though I doubt that the experience of watching fine conversations on film will make us more likely to conduct them. But is there not something quaint in this description? Is that not part of its charm? Although I know that this is not Strong's intent, nor even Cavell's, does this model not smack too much of the liberal theory of perfect discourse? All talk and no action?

Yes, Rousseau thinks human relations, including marriage and politics, are fundamentally erotic, but that certainly does not mean that "mere carnal coition" is the whole of eros. What it means is that passion cannot be extirpated from politics - the wish to do so is inhuman, 
or anti-human. What binds us together in large and small societies is a passionate attachment to one another that cannot simply be talked into existence. Perhaps Milton's Puritan denial, or avoidance, of this point is one factor in his own dismal marital relations. Thus Rousseau disdained any role for the Church in politics but substituted a civil religion - it was not possible, he thought, to have a successful state without a passionate attachment to it on the part of its citizens and some institution to channel that attachment. ${ }^{2}$ Though I did not dwell on this point, it could also be said that one point of superiority of The Rules of the Game (and Greek tragedy) over The Philadelphia Story is the clarity with which it depicts the power, as often destructive as productive, of sexual attraction. Eros is hardly wordless - many volumes of poetry attest otherwise - but the Miltonic model of marriage, to its detriment, avoids a frank discussion of passion's power. However marvelous Milton may be on other points, this is a weakness in his political theory.

In this vein, I am glad that Strong points to Cavell's passionate engagement with the politics of his time. I fear his style hides that attachment too much from his contemporary readers. And, indeed, I do share their disappointment in the debasement of our political discourse. The question is what to do about it. Strong's suggestion comes in response to my reading of The Rules of the Game - we should take the lesson, he claims, that the rules "should have been broken" and that rules "can only be properly reasserted as our own after having been broken" (p. 121).

To this interesting and subtle argument I can only reply in part. First, I am concerned that this depicts the rules by which we live as too much a matter of private conscience rather than of public culture. The rules of property, for example, would be pretty meaningless if we each were free to break and remake them. Living together by rules is difficult because we are not free to remake them at will, even when we may have discovered a better one. That is part of the inevitable cost of housing eros within a stable institution. The Philadelphia Story, I fear, makes light of

2 As Tom Dumm notes, this suggestion was repeated by Abraham Lincoln, no less. 
this cost, as if marriage itself makes no claim on its members but can be whatever they would like it to be. While we are surely not condemned to repeat the institutions of our parents and ancestors, we can see from our current politics how much effort is involved (and how much public effort) in remaking the institution of marriage that we have (and in an innocuous way that harms no one!).

Renoir's characters know better that the rules by which they live cannot be remade at the drop of a hat. They hesitate to break the rules because they know the costs and are not free to change them. The fate of Christine and the death of André are strong evidence of this. I say again that our rules are not as inflexible or immutable as those of chess or poker (and even these, of course, have changed over time). We serve neither God nor nature in obeying them, but this is all the more evidence that long-standing institutions are hard to change, since they sustain themselves without divine or natural support. It is also evidence that, as Hegel understood, they are already ours even before any breaking and remaking that we might undertake.

Second, despite the difficulty of such projects of self-overcoming, there is a danger of romanticizing them so that, as with Rancière, they become the whole of politics, as if we could live a revolutionary life at every moment. The dream of the 1960s dies hard, but it is time to lay it to rest. Living with institutions, I would say, is the real challenge and a project that Rousseau, for all his transgressive tendencies, was committed to, however difficult it was for him. Though Strong is committed to reasserting rules after breaking them, his philosophy does not really tell us how to do so or how to live with them after it has happened. Continuing a relationship is just a less cinematically compelling subject than making or breaking one, and it is hard to imagine that it will be the subject of many "Saturday Night Fevers."

Third, as with the later related claim that the films in question are not about moral behavior but about "what one has to become in order to be capable of moral behavior" (p. 130), I wonder if the argument abstracts away too much from what is clearly depicted, in favor of a conclusion that one already needs to be a moral paragon to reach. In 
any case, my main argument is not that film cannot show us something admirable (clearly it can), but that, even in such a case, the substance cannot defeat the effects of the form. That is, even as a film is giving us something, I worry that it is simultaneously taking something from us that we do not notice until it is too late.

As with Woodford's claims on behalf of exemplarity, I wonder whether the distinction that Strong strives to make on Cavell's behalf can really operate in practice. Even if I grant that the best films show us what Strong claims they show, it is not clear whether the effect of watching is to make us more or less likely to become "what one has to become." If watching Astaire dance does not make us dancers, how much less likely is it that watching moral paragons will make us such? Or, if we simply need assurance that such behavior is possible and yet cannot find it in the world around us, then the film has sailed past optimism and into fantasy.

Setting this aside, my more particular claims about the substance of these films is that the need to please the audience, in cases like The Philadelphia Story, leads them to refrain from addressing the tensions that they touch upon in the most honest way. This brings me to Margaret Kohn's remarks and the challenge that she offers via her analysis of The Americans, a series well suited to our topic since its very title ironically refers to a pair of imposters (actors?) faking a marriage in a country that is/is not their own and in need of moral repair.

I must admit that I am not very familiar with this series, beyond seeing the well-executed posters that dominated that Los Angeles skyline for a few months while it was being launched. But that is not unusual, because it seems that not many of my fellow Americans are watching The Americans. According to what data I could find, the show is seen by three million people at most every week (yes, including those who record it and watch it later). In a nation of over 300 million, that is not all that impressive. I believe it does not even crack the list of the top 100 shows on the air today.

So, I am tempted to say that, whatever the content of this show, it will not "[unsettle] the opposition between popular/ideological and critical/ 
unpopular," (p. 132) as Kohn maintains, and leave it at that. Like The Rules of the Game, it seems to have met with critical acclaim but little love from the public, Kohn's own enthusiasm notwithstanding. Its continued existence seems to reflect something else Kohn mentions much later in her essay: that the changing economics of the television industry has made it feasible to eke out profits on shows with small audiences. ${ }^{3}$

However, that would be a cavalier response to Kohn's very serious effort to alter and expand our understanding of what a remarriage drama might do. I am first of all attracted to the notion that some of the structures of television might be to the advantage of those interested in depicting marriage more realistically. "One of the distinctive features of serialized television is that it is continuous rather than finite," she writes, adding that this allows the show to demonstrate that "Remarriage is still marriage and marriage is work." This is a consideration that the comedy of remarriage in film hardly depicts. The film always ends at the moment of remarriage. However, as a serial television show, The Americans continues well beyond that point. That this is an argument in its favor, I cannot deny. ${ }^{4}$

This does mean that part of the force of Kohn's argument relies on a distinction between the two genres, which she initially rejects in claiming (using my admittedly vague category) that the show is "filmlike." But, like her, I do not think it makes sense to rely too much on genre distinctions here until we have analyzed the substance a little further. Knowing so little about the show, I can only proceed so far, but I have some questions. I wonder, first of all, if the title is even more ironic than it seems. Is this couple, perhaps, intended to be the "real" Americans in the show? That is, is their actorly identity as a married couple, perhaps repaired over the course of the show, a hint that our own political union is less than sincere? The 1980s setting and critique of American foreign

3 It is important to note that the general fragmentation of the television audience has not been matched by a similar phenomenon in the audience for film. A truly popular film in the United States can still reach tens of millions of people in a few days. It has been decades since that was true of any television show. For those tempted to dismiss film as a declining element of our popular culture, it is important to note this fact.

4 Although this is also the structure that permits soap operas and sitcoms. 
policy that seems to be involved in the show surely points in that direction. I wonder, therefore, whether there is a deeper level of insincerity or cynicism (!) about the whole enterprise that might make it less than it seems in terms of a model of remarriage. Can it be a "remarriage" if it was not a real marriage in the first place? I realize, of course, that the whole Cavellian theme of remarriage is predicated on a degree of failure and falseness to the first marriage, but The Americans, from what I understand, takes this to an extreme.

A spy drama that is also a family drama seems to maximize the possibility for secret-keeping among its characters, but, therefore correspondingly, I would say, for the quasi-pornographic enjoyment of its viewers. Kohn wants to argue that we learn from the moral ambiguity of the characters or their situations. I would be inclined to guess that whatever popularity the show has results less from this element than from the endless opportunities it affords to peek into a scene that is usually unseen (espionage, a marriage, affairs, etc.). Again, I insist that we must ask not what intelligence might have written the script, but what emotion keeps the viewers seated? Kohn is leery of her own attachment to the series - is this perhaps the reason? Does it offer an endless number of veils to be torn away, one after another, like a roller-coaster of peeping?

My view is not just that, as film viewers, we are lotus-eaters; it is worse than that. My concern is that we actually dull our capacities for engaging with others by enjoying ourselves with the simulacra of personality that we encounter on screen. Kohn offers some reasons why this might not be so. I acknowledge, of course, that we may discuss television shows and bond over them. But, I ask again (and by now the reader is no doubt a little tired of this), if this is the Golden Age of Television (and who am I to doubt it?), then where is the "Golden Age of Politics" or "Friendship" or "Conversation" that is supposed to result? Why should we be afraid to draw a conclusion from the simple correlation that our politics seems to have gotten worse while our television has gotten "better"? Whatever good may come from the reflections Kohn describes, why should we believe that it is not outweighed by the known drawbacks? 
Kohn says we are clearly all Parisians now and "there is no going back to the real or imagined time when we spent our evenings in serious conversation, political action and musical performance" (p. 144). That we cannot reverse time is beyond dispute; nor would I want to. But that is not our only choice. In reality, we do not face one big decision of whether or not to "have" film or television. Rather, we face a thousand smaller decisions. Shall I watch a film on my phone as I eat dinner? Shall I let my children watch a show or make them read a book? Shall we subsidize the film industry and penalize printing? Shall I take my beloved to the movies or take a walk in the Hollywood hills? Shall I write a letter or take a selfie? We need not answer all these questions in the same way, but we must have some principles to live by in answering any of them. Are we satisfied to let our lives, our culture and our politics be dominated by screens or do we choose to resist that domination? Why do the prophets of total revolution quail at the idea that we might attempt to limit our consumption of screened images? This is not a domination we can overcome perfectly or completely, but to collapse without a fight will hardly be thought a brave decision by our descendants, who will have their own aesthetic, technological and political challenges.

I am glad, for more than one reason, to see Davide Panagia ascribe godlike powers to film. I would not have put it that way, but in some sense I agree with him, and it is this agreement about film's power that forms the basis of a political disagreement of no small importance. For he would have us bow down to this new god while I would have us resist, to the last, anything that makes our human world less human. Democracy needs gods like it needs a hole in the head. As Rousseau well understood, any uncivil religion locates a moral authority beyond the people and therefore undermines their political authority. The people's choices are then always second best. Democracy must make its own standards of judgment - is that not the true Emersonian legacy?

I am glad, in the second place, because Panagia gives me grounds for answering one of his other objections to my argument, one that I have heard before from other quarters, and found difficult to counter. "Is 
reading not equally something," he asks, that isolates us and therefore defiles our social capacities (p. 159)?

When this question has been put to me, I have tended to concede the point, to admit that my critique of cinema must apply to some of the other arts as well and to wonder whether I could find grounds for saying that it applied less completely. But now Panagia has supplied the ammunition I have been seeking by insisting that cinema has a special world-creating capacity that the other arts have sought but never fully possessed. I want to agree with him, because that agreement would excuse me from the task of differentiating film from other media and supply perfectly what my argument otherwise lacks, a simple way to differentiate films from novels and paintings and the like. All these arts "absorb" their viewers to a degree, but film absorbs us in a special way because it can completely immerse us in another world like no other media, though perhaps it will be superseded in this by future artistic technologies.

"One says this, and then one hesitates." Shall I really admit the existence of a god within our world and then deny her proper respect? Perhaps I can find a better response in another register.

I am very struck by Panagia's invocation of Benjamin and the concept of "play" as an alternative vocabulary with which to defend the democratic potential of the medium of film. A quick reply to this contention would be to say that Benjamin was simply wrong to look to the films of Charlie Chaplin as an encapsulation of the medium's aesthetic potential, though this was a very common move in cinema criticism before the World War II. While Benjamin may (perhaps) have been correct that Chaplin's antics would have worked less well on stage (although Chaplin began his career in vaudeville), still I'm not sure that we can say that his films fully demonstrate the kind of world-creating absorption of which we know the medium to be capable.

But this kind of response is clearly insufficient. I reply to Panagia's invocation with one of my own: Hans-Georg Gadamer. It is not often remembered today that Gadamer's Truth and Method also has at its core a theory of absorbing play as an essential model for human activity and even art. But, for Gadamer, this account points us in the direction 
of language and dialogue - that is, reciprocal exchange - as the core practice for human beings, something quite at odds with Panagia's contention that we can find play in the experience of watching a film.

Gadamer's account draws from history, etymology and anthropology to argue that our many uses of the term "play" center on the "to-and-fro movement that is not tied to any goal that would bring it to an end ... rather, [play] renews itself in constant repetition." ${ }^{5}$ Play, and absorption in play, are exemplified in this account by the way in which we become part of a shared activity with other people, where we participate in an exchange that involves each of us, at some point, taking action. The game provides a structure for our interaction, but while we engage we do not think much of that structure, but only of our actions in the game.

In this sense, a game is like a conversation, in that we do not think of the rules of grammar and syntax while we converse but only about what we, and the other people involved, are saying. We think of the substance of our exchange and of the other people with whom we are conversing. Whether we win or lose a game (or an argument), the activity is a reciprocal one between equals, an equality that is recognized by our very participation in the activity. Many games (like catch) as well as (non-forensic) conversations do not have winners or losers at all, but still have the essential game structure of reciprocal equality.

Just for this reason, Gadamer writes, games "are in danger of losing their real play character precisely by becoming shows."' Though a contest might be exhibited for others, it gets the character of play from having equal participants. This might even include art, for Gadamer, so long as the audience is a necessary participant in what is created. But, as Panagia reminds us, film does not need its audience (as novels and even theater plays do) to create its worlds. If we value play as a model of equal, open-ended participation and engagement in a joint process that is equally contest and cooperation, we must guard against

6 Ibid., p. 109. 
its deterioration into something that mimics this form but is in fact one-sided. Perhaps it is correct that novels and theater are already too imbalanced in this regard, but with film we have reached some kind of apogee.

When Benjamin spoke of films as containing room to play, he was perhaps thinking of the creative freedom that they afford a certain category of artists (and, again, in the context of Charlie Chaplin and Buster Keaton, this seems understandable). But, if he meant that the exchange between a film and its audience was one of play, I would have to conclude that he was deeply mistaken. There is no equality in such a relationship, indeed there is a hardly anything that you would want to call an exchange. The throwing is all on one side and the catching all on the other. Again, we may have a wonderful conversation about a film after it is over, but to say that we have a conversation with a film is to display a sadly depleted idea of what it means to have a conversation or to play a game.

Here too is a better response to Panagia's claim that my concern for the cinematic citizen might be extended to the reader of novels. Gadamer points to language as the essential medium of democratic equality; it is through language that we engage each other as equals, hear one another out, and agree or disagree while retaining a relationship of parity. Even an encounter with an ancient text whose author is unknown can result in a conversation.

Gadamer does think of art as something with which we can have a conversation. Although he discusses many art forms in his book, he has little to say about film, and for good reason. First, as Panagia maintains, film is autonomous from its audience, independent from their imagination and judgment, in a way that other arts are not. Films contain language, to be sure, but if there is anything that generations of film theorists have agreed upon, it is that film is primarily a visual medium. But, unlike dance or theater, the presence of the audience is not necessary to distinguish rehearsal from performance. Its ontological properties, whatever they are, will not be easily equated with those of text. For all these reasons, it is hard to understand an interaction with film as a dialogue. 
I confess that Gadamer's aesthetics is inadequate to film - he has no good vocabulary for expressing film's artistry, as does that of M. Cavell. But it has never been my claim that film is not beautiful, or powerful, or fine. It may be all these things, but it is not a medium, like language, which installs equal reciprocal exchange at the ground floor of its being. It is because I want no gods to violate the equal reciprocity necessary for democracy that I want no films to violate it either.

The play theory of language, it seems to me, gives expression to a crucial element of Rousseau's theory of human equality. We are not equal by virtue of God's fiat, nor by some biological fact about our physical constitution. Neither are we unequal by such measures. Rather, we are equal politically by virtue of our mutual constitution of one another as humans, by means of a reciprocal exchange, something that happens through language. There are many different practices that can draw upon and extend this process, but not all human activities do so. Some retard it. Whether cinema is an art or a god it is not a partner to this process, but an opponent to it, a powerful one.

So, things can be truly shared in language - as a game is shared disagreement as easily as agreement. I do not believe it is optimistic to say so. Optimism would mean believing that language had some natural power over the opponents of this sharing when it seems more likely that the reverse is the case. We must protect this element of our culture and politics and not assume that it is so fundamental that it does not need protecting. Well-wrought constitutions may afford us some of these protections, but they are certainly not idiot-proof - we can break them with our idiocy, even a culturally induced idiocy. (Taking "idiot" in its original meaning of someone so private - so disengaged from conversation with others - that he or she has no interest or aptitude for public affairs.)

I have no objection, I should say, in film forming some part of our democratic curriculum. Like all powerful and dangerous objects, it should be studied and that study may well be part of our political education. But, just as ballistics is a necessary but unhappy science, so I think should we regard the study of film as an important field without 
hoping that our need for it will expand indefinitely. Naturally, some will fall in love with this field, as happens with all the forensic sciences. That makes them no less morbid pursuits.

Tom Dumm: Felicitations on your meet and happy nuptials! I hope you will enjoy many years of marital concord! I am sorry, though, that your happiness put you in the wrong mood to hear my unhappiness, which is not with real relationships and places, such as those that currently occupy you, but with their representations. Surely you would not suggest to those who lack partners and homes that they be satisfied to see The Philadelphia Story any more than one would suggest to the hungry that they enjoy My Dinner with Andre? No, where we disagree can only be with regard to what role these representations can play in our democratic culture.

Is Cavell naive? I do not think so. Insensitive to danger? Probably not. Whiggish? Well, there we may disagree. I do not know if pessimism is the "only legitimate response" to our world but, as you know, in my opinion it is one of the best. And, from that perspective, yes, Cavell's perfectionism does look a bit Whiggish despite his many disclaimers. Cavell's optimism is not Kant's or Hegel's; it is Emerson's. But, it is real enough. There is, after all, a reason that Emerson is on every American high-school curriculum and it is not his complex and sensitive treatment of democratic culture. There is a bit of faith at the core of his account of the growth and development of the soul and some of that faith I think has found its way into Cavell's perfectionism. I have long thought that this reliance on the future as a cure for the present was the basis for Nietzsche's lament: "In Emerson we have lost a philosopher." I would not say that of Cavell, but I do think there are moments when his hopes get the better of his judgment.

I am glad you perceive that, in the end, my questions are ultimately not for Cavell but for democracy and cinema, and especially, I would add, for our modern representative democracy. You do not trust Rousseau as a democrat? I reply that, on formal terms at least, Rousseau is the most democratic figure in the traditional canon of political theory. It is he, and only he, who insists not only that equality is a fundamental 
principle and that slavery can never be justified, but also that every law must have the direct authorization of the majority of actual individuals for it to be legitimate. Not even the Levellers go so far. Neither Mill nor Kant, Emerson nor Cavell say anything like it. While democracy as a concept has become increasingly popular in the last two centuries, the burden of most democratic theory today is still to separate political power from its direct exercise by majorities, and then to justify that separation.

So who, really, is the unwashed democrat here? The unvarnished one? Shall we praise democracy as we find it (when we find it), or as we hope it will be, a democracy to come (as Derrida puts it)? No doubt political theory should elaborate ideals and give voice to them, but we cannot become the captives of our own fantasies. We cannot mistake the democracy for which we wish for what majority rule today would mean. I am more inclined to think that those who hesitate to embrace Rousseau's enthusiasms are the ones who are truly wobbly on democracy. It is marvelous to believe that democracy has a future of increasing perfectibility, but is it an act of faith or reason to do so? If you sense some hesitation on my part, it is not because I lack imagination but because I read the polls.

I find much to agree with in your defense of (and Cavell's insistence on) "the multiple and complex crossings of private and public so necessary to following a life worthy of existence" (p. 171). I do not think our disagreements lie here. But I do share Arendt's concern, not that public and private know their separate places, but that the public as we know it may simply disappear. Surely your rightful concern for the politics of the ordinary does not blind you to the many forces that eat away at the ability of our citizens to care for and speak to those outside their daily circle of activity. We are encouraged by many economic and social forces to turn inward, not to our souls but to our families, our jobs, our hobbies, until we have little contact with those with whom we are supposed to be democratizing. Will film counter this tendency? I am concerned that it gives us a feeling of participating in something greater while in fact it substitutes for that participation and makes it less likely. 
How can I answer your blunt questions about a memory when, as you rightly say, memory is inclined to play us false? It was 1979; I was 14; I swear I had never even been to North Carolina! Beyond that, what can I really know for certain? Like a character in Rashomon, I speak truthfully but only out of my own recollection. I am really too young for The Andy Griffith Show. If I were tempted by nostalgia, its color would be more like Bewitched, Gilligan's Island and Happy Days (all sadly unwatchable now). For inspiring musicals of liberation from custom and censorship, I would take The Commitments over Footloose any day (and Guys and Dolls over The Music Man). But I am not nostalgic and I really think that you have largely misunderstood me here.

Who is really the censor in this debate? Who is the one issuing judgments of quality and edification? I am not the one making the distinctions between those films that are "good film" and those that are ... - what word would you have me use? Bad? Evil? Less than good? Some such distinction is what Cavell's aesthetics require, though he chooses largely to ignore those films that do not appear in his canon. I do not really judge individual films at all here, but the institution in which we receive them.

Nor have I - not once - argued that our citizens will lose some kind of native virtue by their exposure to cinema. My argument is, in the main, ontological. I claim that we lose the experience of equal reciprocity in the cinema and find it replaced with a pleasurable experience of power. The loss is political and not moral. Whatever we do afterward, in the movie we give up the presence of other humans and replace it, as Cavell says, with a "human something" that does not make demands on us as a real conversation partner would. It is the fragility of the reciprocal exchange that should concern us. The morality of the humans who carry it out is of less concern to me. I have no nostalgia for village life; if anything, it is life in cities that increases our exchange with others, though not in the cinema.

I have already given above, in response to Margaret Kohn, some of the reasons why I think that the ubiquity of film today is no answer to my concerns. While we may not be in a position today to close 
the cinemas, we still face many questions about whether to resist, or enhance, the cinematic qualities of our political life. There are recent books (like Jeffrey Green's The Eyes of the People) that suggest democratic citizens in a modern state should resign themselves to the role of spectators. I do not expect you would agree with that at all, but I think a stronger defense against such a position is constructed when we acknowledge a general danger of passivity in the cinematic situation, rather than celebrating cinematic edification and implausibly claiming it as a source of activism.

So many of the laws governing our practices of citizenship (in areas like voting, federalism, campaign finance, corporate "speech," assembly, etc.) reflect, at least in part, our sense of what it means to have representatives in a democracy and how we can and should relate to them. All of these, I would say, can be more or less cinematic in many particulars. Perhaps, in a large country, we "must" have representatives in the same way that, as a modern country, we "must" have cinema. But that does not mean that we have no choices about how we have them, to what extent, and what rank we give them. All this, to me, is what is at stake in this debate. I am surprised that you think otherwise.

Is it really from Cavell that your taste for anarchy and The Ramones springs? Somehow, I doubt it. Did you know I once saw the The Ramones play live? That was a democratic experience: very loud, crowded, slightly violent, corny, boozy, invigorating, and a better date than any movie. But their recordings never meant as much to me there's a difference, after all, between seeing someone perform in front of you and hearing a human something through a machine. Still, your comments and those of Tracy Strong, too, make me realize that there is something about music and film together that I have not yet come to grips with. I hope to do so in the future. In any case, at future concerts, I will look for you in the mosh pit. I think it more likely that you would be there than M. Cavell.

If pessimism is truly at the heart of Cavell's pursuits, as Panagia contends, then the fault is mine for not perceiving it more clearly. But, in the end, I do not write for the Cavells, who are past hearing, but for the 
rest of us. Perhaps Tom Dumm is right that cinema is not the greatest challenge that our democracy faces. I would suggest that it is a challenge that contains many others, most of all what it means for us to live together in the presence of other humans and to do so freely. For, whether we close the cinemas or leave them open, we shall not come to know our fellow citizens in darkened rooms, lit from behind, where we all face in the same direction, never seeing one another, as if chained from birth. 